\title{
Deakin University
}

\author{
Maria Takolander
}

\section{Grounding the 'auto-intoxicated' Romantic poet: A socio-material theory of poetic praxis}

\begin{abstract}
:
This paper engages with the archetype of the 'auto-intoxicated' lyrical poet (Moffitt 2005: 34 ) associated with the Romantic tradition. The archetype is of interest because it continues to inform theories of creativity, including in the discipline of psychology, where studies examine character traits or cognitive processes as if creativity resides in distinctive patterns of thinking alone. It is also present in creative-writing classrooms that insist on their role in cultivating an innate talent and unique voice. Following a socio-material approach to creativity, this paper argues that creativity must be understood in a broader context that extends beyond the paradigm of the special individual. This necessitates considering both the creative practitioner's embodiment within a social or institutional network and also the affordances and constraints of creative materials, which are themselves enacted within social and cultural frameworks. This paper focuses on the generative agency of materials or media when it comes to poiesis. The goal is to provide a more rigorous understanding of poetic creativity and to lay the foundation for a way of teaching poetry that better serves contemporary apprentices in the craft, particularly in a time of medial change.
\end{abstract}

\section{Biographical note}

Maria Takolander is an Associate Professor of Writing and Literature at Deakin University in Geelong, Victoria. She is the author of numerous papers theorising creativity, as well as being an award-winning fiction writer and poet. Her most recent books are The End of the World (Giramondo 2014), which was reviewed in the Los Angeles Review of Books, and The Double (and Other Stories) (Text 2013), which was short-listed for the Melbourne Prize for Literature. She has won two Australia Council grants and is currently finishing a novel for Text Publishing.

\section{Keywords:}

Creative Writing - theorising creativity - poetry - Romanticism - media. 


\section{Introduction}

In Assaulting Parnassus: Theoretical Views of Creativity, the psychologist Jock Abra introduces his study of creativity by asserting that the "true genius is . . qualitatively different from the rest of us' (1988: 10). He provides an overview of various characteristics typically said to differentiate the creative genius from the rest of humanity, according to retrospective psycho-biographical analyses of those with the 'rare and special' gift (10). These include 'flexibility of thinking' (25), 'tolerance for ambiguity' (29), belief in an ability to 'manipulate the world around them' (31), 'insecurity' (31), 'paradoxical personalities' (33), 'naivete' (37) 'alienation' (38), 'selfishness' (43), and anti-authoritarian impulses (44).

Other studies, which I have addressed comprehensively elsewhere (Takolander 2015, 2016), often using a similar psycho-biographical methodology, characterise creativity as the outcome of a pathology or disorder that gives rise to the same kinds of personality traits outlined above. In Touched with Fire: Manic-depressive Illness and the Artistic Temperament, for example, Kay Redfield Jamison argues that manic depressive illnesses are common amongst great artists, bringing about the kinds of symptoms that are often associated with creativity: 'restlessness, ebullience, expansiveness, irritability, grandiosity, quickened and more finely tuned senses, intensity of emotional experiences, diversity of thought, and rapidity of associational processes' (1993: 105).

A number of criticisms might be levelled at such studies. Of primary concern to this paper, however, is how these scholars of creativity in psychology and psychiatry, unschooled in cultural history, unselfconsciously subscribe to what Vlad Petre Glaveanu calls the 'He-paradigm' of creativity, with the pronoun providing 'a symbol of otherness' (2010: 149). Such an individualistic ideology of the artist, while assumed as given, is neither timeless nor universal. In Inspiration: Bacchus and the Cultural History of a Creation Myth, John Moffitt tracks how 'the ideal of the wholly autonomous, creative personality' developed in the West (2005: 191). He begins by identifying, during the Renaissance, an emerging transformation of the artisan, who was trained and worked in a tradition, into an elite 'Artist-Priest-Prophet' (37). For Moffitt, this transformation relied on the re-envisioning of classical images of Bacchic intoxication, and on the concomitant consolidation of a Liberal Arts tradition for the leisured classes based on 'Art-Worship' (267). The invention of the printing press was central to the cultural shift, facilitating the transition away from an oral tradition and enabling differentiation of the inspired creator (who did not operate the printing press) from the unoriginal scribe.

However, according to Moffitt, it was the Romantic period that consolidated the notion that only 'particularly favored, individuals' are bequeathed with the gift of creativity (15). Combining Bacchic images of 'auto-intoxicated' (34) inspiration and the emerging mental sciences (themselves inseparable from the rise of individualism), Romantic poets invented the personal lyric (against the national ballad), and styled themselves as melancholic, mad, rebellious or visionary in ways that helped mythologise their singularity and the singularity of their product. As Moffitt puts it, the Romantic ideology of individuality is indivisible from the contemporaneous 'principle of free mercantile competition and the right of personal enterprise and individual initiative in commerce' (191). Indeed, it is during this period that the commodity of a creative practitioner's originality began to be protected by copyright law.

Romantic poets, as Duncan Wu argues, have since been 'abstracted ... to the point at which they have been divorced from the reality of their own lives' (2015: xiii). However, as $\mathrm{Wu}$ suggests, consideration of their actual creative practice resolutely undermines the myth that Romantic poets were 'solitary geniuses' (42) whose literature arose from 'spontaneous inspiration' (49). To begin with, the Romantic poets were friends and 
collaborators, immersed in publishing networks and literary coteries, often even dirtying their hands with the printing press and processes of self-publishing. Wordsworth, as Wu outlines, was 'acutely sensitive to his audience, and tailored his work to their needs' (43), while Shelley, who gave his publisher a list of individuals and newspapers to whom to send copies of his books, was 'fully engaged with the mechanics of the trade in which he was enmeshed' (44). Revealing the function of coteries in establishing reputations, Wu reveals how 'Keats was a victim of literary factionalism' (43). Further undermining the solitary nature of creative practice, $\mathrm{Wu}$ points out that Blake's wife Catherine helped draw, engrave and colour the multimodal books mythically attributed to Blake's visions (43). Thus, what the Romantic poets actually demonstrate, in Glaveanu's terms, is a 'Weparadigm' (2010: 148) of creativity, which stands opposed to 'the iconic image of the solitary genius' (149) and demonstrates how individuals are 'creative only in their relation to one another' (148).

It is also the case that the canonisation of a handful of Romantic poets (Wordsworth, Shelley, Byron, Coleridge, Keats, Blake) from amongst multitudes, enhances a misleading impression of their singularity, such that, as Daniel Allington suggests, the 'cult of the creator' (2011: 286) might be regarded as an 'illusion born of forgetfulness' (282). As Allington reminds us, by drawing attention to the retroactive processes of evaluation apparent in canonisation,

creativity is not an objective property: not something that can be present in or absent from particular people, acts, texts, utterances, etcetera. It can only be ascribed, which is to say that it is always a function of social interactions that - often retrospectively, and always provisionally - produce particular people, acts, texts, utterances, etcetera, as creative or non-creative (277).

The post-Romantic image of the creative practitioner as an individual inspired by a unique vision, however, is a powerful one. This is because, as Pierre Bourdieu argues, the "charismatic" ideology" of the creative practitioner is at once the foundation of the creative industries but also 'the main obstacle to a vigorous science of the production of the value of cultural goods' (1993: 76). He explains that it is 'this ideology which directs attention to the apparent producer, the painter, writer or composer, in short, the "author," suppressing the question of what authorizes the author, what creates the authority which authors authorise' (76). For Bourdieu, the 'quasi-magical potency of the signature' can only be understood within a cultural field of agents and institutions - publishers, critics, academics, coteries, reviewers, gallery owners, dealers, et cetera - through which 'the value of works of art and belief in that value are continuously generated' (78). He argues: 'The unnatural idea of inborn culture, of a gift of culture, bestowed on certain people by nature, is inseparable from blindness to the functions of the institutions which ensure the profitability of the cultural heritage and legitimise its transmission while concealing that it fulfils this function' (235).

To escape this 'blindness' to the constitutive contexts of creative practice, this paper follows Mihaly Csikszentmihalyi's ground-breaking systems approach to creativity, which examines the interaction between an individual, a social field, and a cultural domain (1988: 325), supporting a networked, distributed and emergent view of creative practice. According to Csikszentmihalyi, 'we need to abandon the Ptolemaic view of creativity, in which the person is at the center of everything, for a more Copernican model in which the person is part of a system of mutual influences and information' (336). However, this paper takes its primary inspiration from Lene Tanggaard's 'socio-material analytical point of view,' which 'underlines that materiality and artifacts are to be seen as substantial components of the process of creativity' (2014: 110).

Tanggaard focuses on the particular art or craft - with the latter term regarded as a less mystificatory version of the former - of design. Design usefully foregrounds how the 
affordances and constraints of materials function as agents in the creative process, for design 'is nothing without materials' (133). However, Tanggaard's insights about the generative role of materials are also valuable for understanding how poetry emerges in its particular domain.

It is the argument of this paper that understanding poiesis as a sociomaterial practice - as an activity that emerges in relation to materials or media in a social and cultural context - is important, facilitating not only a grounded appreciation of how poetry is made, but also a grounded rationale for how poetry might be taught in University classrooms. Embracing the role of materials or media when it comes to poiesis has particular relevance in our time of medial change, preparing students of poetry to be responsive to rather than defensive about the new media or 'writing' technologies that have the potential to reshape literature.

\section{The 'Medial Turn'}

In his Defense of Poetry, Shelley claimed that 'when composition begins, inspiration is already on the decline' (1965 [1840]: 135), thus consolidating, as Andrew Piper suggests, the Romantic ideology that literature 'is what happens in the mind, not on the page' (2009: 12). Indeed, as Piper puts it, the Romantics established an 'opposition between technics and aesthetics that is in many ways still operative today' (12). This opposition is apparent in the psychological studies of creativity canvassed at the beginning of this paper, in which the focus is on the individual, and in which the material field of composition is invisible. It is also evident in the popular University of Iowa Writers' Workshop credo, advertised on their website, that 'writing cannot be taught' but only 'developed,' and that the success of their graduates is 'more the result of what they brought here than what they gained from us.' It is an individualistic philosophy of creativity that permeates writing classrooms the world over - and one not incidentally coterminous with the 'charismatic' ideology of creativity that defines the commercial field of cultural production, as theorised by Bourdieu. However, the limitations of this vision of creativity are profound, particularly if one accepts the University's role in fostering knowledge - and if one embraces the future opportunities associated with a changing media landscape calling for creative practitioners to engage with digital technologies. If we understand education, as Svend Brinkman and Tanggaard recommend, not as the 'transmission of stable ideas across generations' but as 'a way of reconstructing social relationships ... that enable human beings to respond to the changing world in which they find themselves' (2010: 244), then we need to stop romanticising the 'lonely individual genius' (256) and situate creativity as a dynamic 'form of doing' (256).

In 'The Socio-Materiality of Creativity: A Case Study of the Creative Processes in Design Work,' Tanggaard extends her challenge to the Romantic legacy of creative individualism by focusing on 'materials and artifacts as creative actors in ... real-life creative processes' (2014: 111). Tanggaard acknowledges the influence of Bruno LaTour's Actor Network Theory (2005), which challenges the paramount importance traditionally accorded the human subject and broadens the diversity of 'actors' in any network to include objects, in line with scientific theories of distributed cognition. Tanggaard's approach forgoes interest in 'the creative individual,' as defined by 'measures of personality traits or cognitive abilities,' and instead attends to the 'inviting properties or intentionality' of objects in the 'socio-material relational space' of creativity (2014: 111).

For her case study, she analyses the work of a ceramics designer commissioned with the task of creating a product line of crockery based on the art of the Danish painter Bjørn Wiinblad. Her research emphasises how creative practice is always located in a worldly, even commercial context - even if another creative practitioner might alternatively figure 
her work in resistance to that context. Tanggard's example also highlights how creativity inevitably arises from within a cultural tradition, which includes both the work of predecessors and preceding conventions associated with the use of materials. Thus creativity is both more socially situated and revisionary then usually acknowledged in individual-centered theoretical studies, which imagine the creative individual in Romantic opposition to the social world and existing culture. Tanggaard argues:

when we are creative, we rarely produce knowledge that is wholly detached from the prior knowledge of ourselves and others. It is perhaps more a matter of repackaging knowledge, of recreating something that previously engaged us, of improvising on the basis of knowledge that we already master, possibly of retrieving something that we had once forgotten (2012: 26).

Creativity, of course, has been conceived of as intertextual and revisionary before, but to turn attention to how materials and their histories are themselves involved in the revisionary process is a significant innovation. Certainly, the affordances and constraints of materials - implicated in 'the materialized coming into being of things' (2014: 122) are of primary concern in Tanggaard's work. For Tanggaard, 'a material can be regarded creative in its confrontation with people, who respond to the object's hardness, its softness, or whatever the object can do for them' (2012: 24). The fact that these creative materials 'have a history, communicating pre-existing ways of doing' (2014: 114), is also integral to the creative process.

Tanggaard's materials-based approach to understanding creativity is also useful for thinking about poetic creativity or poiesis. For Tanggaard, 'it is contact with or resistance from the materials with which we work that causes new ideas to arise ... even if the immediate experience may be that the good ideas pop into our heads' (2012: 25). When it comes to writing poetry, contact with or resistance from compositional materials spoken words in an oral tradition, pen and page, the keyboard and screen - generates a dynamic response always embedded in the (disremembered) agency of those materials, which cannot be separated from their contexts and histories of cultural use.

The materials of writing have come increasingly into view as digital technologies contest a print-based culture - just as the advent of radio, film, television and computers was crucial to the re-engagement with textuality that distinguished modernist and postmodernist culture. As $\mathrm{N}$ Katherine Hayles and Jessica Pressman argue in Comparative Textual Media: Transforming the Humanities in the Postprint Era, 'when writing was accomplished by a quill pen, ink pot, and paper, it was possible to fantasize that writing was simple and straightforward, a means by which the writer's thoughts could be transferred more or less directly into the reader's mind' (2013: ix). However, as a result of 'the proliferation of technical media ... that illusion became much more difficult to sustain,' making mediality 'a central concern of the twenty-first century' (ix).

In Writing Space: Computers, Hypertext, and the Remediation of Print, Jay David Bolter similarly argues that new media technologies have exposed how the 'writing space' has always been 'a material ... field, whose properties are determined by a writing technology and the uses to which that technology is put by a culture of readers and writers' (2011: 12). He argues that 'the literate mind is simply another name for the collective decision shared among writers and readers about how to exploit their materials in order to communicate' (17). However, Bolter also recognises the distinctive importance of textuality to conceptualisations of human identity. He suggests that each writing space from the oral to the papyrus scroll to the codex to the computer screen - has been contemporaneously figured as a 'metaphor for the human mind' so that 'it becomes difficult for a culture to decide where thinking ends and the materiality of writing begins, where the mind ends and the writing space begins' (13). 
For example, orality was inextricable from a 'communalised and externalised' understanding of the human mind, as Walter Ong argues in his landmark study of the cultural transition from orality to literacy (2013: 68). Subsequently, the privately consumed and linear medium of the manuscript, on which the writer was able to concretise and reflect on his or her words as if they were a manifestation of an empirical consciousness, is inseparable from a Cartesian and individualistic understanding of human cognition (as epitomised by the philosopher René Descartes' credo 'I think therefore I am'). Indeed, Bolter notes how, with the emergence of Romantic bibliophilia, 'Western culture came more and more to anthropomorphise books, to regard each book as a subject with a name, a place (in the library), a voice, and a bibliographic life of its own' - all ultimately 'sanctioned by copyright law' (2011: 79). Judging by the at-times hysterical reactions to the 'threat' of the digital medium - itself accompanied by a shift to a distributed and more visually dominant understanding of cognition - and the nostalgic reaffirmation of the codex, it is an individualistic and Romantic concept of the self that the field of cultural production is reluctant to surrender.

Such reflections about the connections between writing materials and models of human cognition are not meant to reinscribe the technological determinism for which media scholars such as Ong and Marshall McLuhan have been criticised, but simply to acknowledge, as Bolter argues, that 'the technical and the cultural dimensions of writing are so intimately related that it is not useful to try to separate them: together they constitute writing as a technology' (19). We are dealing with, as Sakari Taipale writes, 'knotty relationships where the material basis of the practices (e.g. pen, paper, keyboard, screen) meet the images and meanings of the practices' (2015: 268). These 'knotty' relationships are also deeply affective. The culturally invested and emotional nature of our interactions with media are apparent in recent defences of the printed codex, such as Steve Birkert's The Gutenberg Elegies: The Fate of Reading in an Electronic Age (1994) and Nicholas Carr's The Shallows: How the Internet is Changing the Way We Think, Read and Remember (2010). Emily Dickinson's authentication of the hand-written and handsewn 'fascicle' against the mass-produced codex provides an interesting comparison and counterpoint, demonstrating the historical and cultural relativism of our thoughts and feelings about different media.

The cultural and emotional nature of our interactions with writing materials is also evident in emergent empirical research conducted on student writers and readers. As Leopoldina Fortunati and Jane Vincent document in their sociological study of Italian students and their attitudes to chirographic versus electronic media, the materials of pen and paper are associated with qualities such as freedom (2014: 44) and individuality (45). Even the smell of ink on paper lends the materials a greater sense of 'aesthetics' (45). Indeed, according to Taipale's similar Finnish study, 'students are much more verbose when elaborating on the bodily aspects of using pen and paper - both for reading and writing than when addressing a keyboard and a screen' (2015: 770). By contrast, as Fortunati and Vincent report, electronic writing is associated with 'de-personalization,' 'decontextualization' and 'opportunities for distraction' (2014: 7). Such perceptions, as Taipale suggests, must be understood within the context of an intermedia environment in which 'traditional values and positive images associated with the book ... are easily taken for granted even by people who do not actively read books' (2015: 770) and in which new digital technologies have provoked the nostalgic valorisation of older materials as more transparent and authentic (a trend also apparent in the music industry).

However, as Bolter points out, there is no escape from the fact of mediation: 'writing with pen and paper is not more natural, no less technological, than writing on a computer screen' (2011: 17). Even traditional oral poetry, prior to the invention of literacy, was mediated through rhythmic and formulaic strategies of composition. Indeed, it is the 
argument of this paper that poetry is an especially productive case study for sociomaterialist analysis. As Adam Hammond argues in Literature in the Digital Age, the ancient craft of poetry has endured from oral cultures through to the digital age and 'is the literary form that has been most affected by medium shifts' (2016: 73). It is also the case that the nature of poetry, in each of its medial incarnations, is inseparable from its compositional materials, starting with language itself.

\section{The Materials of Poetry}

The ways in which the history of an art form is inextricable from the history of its materials is often underestimated. When it comes to poetry, the importance of media is perhaps especially overlooked, given the dual legacy of an oral tradition, which gives a misleading impression of immediacy, and of the Romantic mythologisation of the independent genius, which renders materials immaterial. However, the defining importance of media is manifestly evident in the history of poetry.

Language is the fundamental material of poiesis. In fact, given that the roots of speech are located in emotional responsiveness and gesture (Merleau-Ponty 1976, Dissanayake 2000), one might describe language as a material that humans generate in social and embodied ways that are intrinsically creative. While the psychologist Abra may uphold the 'rare and special' quality of creativity as something essential and apart (1988: 10) even polemically suggesting that creativity lies beyond 'our sense of democracy and fair play' (11) - contemporary research has shown that everyday speech is generated through medial strategies more usually associated with the craft of poetry. Ronald Carter's Language and Creativity: The Art of Commontalk (2004), for instance, examines the CANCODE corpus of spoken English, an archive of recordings of ordinary speech, and identifies how routine expression and communication is enabled by repetition, wordplay, embellishment, humour, hyperbole and metaphor, among other poetic techniques. Such research renders poetry, as an art form, less a feature of the individual genius than a series of embodied and contextual techniques for generating language, which are then cultivated or refined by poets into a formal medium.

Certainly, oral poetry amplifies the characteristics of everyday speech into an institutionalised techné. Oral poetry is afforded and simultaneously constrained by mnemonic and generative strategies, which are, as Ong puts it, 'heavily rhythmic' and 'shaped for ready oral recurrence' in 'balanced patterns, in repetitions or antitheses, in alliterations and assonances, in epithetic and other formulary expressions, in standard thematic settings ... in proverbs' (2013: 34). As a result of the ephemeral medium of orality, the poetry materialises in ways that are, as Ong points out, characterised by aggregation, redundancy, provisionality, the agonistic, 'heroic' rather than 'colorless personalities' (69), non-sequentiality, and an episodic nature.

It is easy to imagine that, in ancient Greece, the poet would have appeared to mysteriously channel stories through the rhythmic and embodied strategies of composition. However, it is important to note that the classical and Bacchic notion of the divine or inspired poet - reappropriated during the Renaissance and the Romantic era, according to Moffitt's study, as we saw earlier - was not about mythologising an individual's genius in a way that separated them from tradition. By contrast, the concept of Bacchic intoxication was an attempt to explain how a poet came to be uniquely empowered by a tradition - and its material techniques of emergence (exemplified by oral skills of versification) - on behalf of a collective. It is notable that contemporary performance poetry continues to rely on traditional mnemonic and embodied strategies of rhythm and rhyme in order to enact poetry of social or political significance. And every working poet - even the poet of the 
page - understands how rhyme generates or materialises poetry in ways that feel mysterious but that can be explained as an affordance integral to language.

When poetry eventually came to be visually constructed in chirographic form, the voice was suppressed but only ambiguously, for oral techniques are echoed in the formal arrangement of the poem on the page. Lineation and stanzaic representation, for instance, essentially represent the overarching speech patterns and episodic structure of oral verse. This ambivalent relationship between new and old media, characterised by suppression and revitalisation, exemplifies the strategy of 'remediation' described in Bolter's and Richard Grusin's landmark study of that name (2000), which describes how each new medium both suppresses and revitalises an older medium. Coining the term 'intermediation' to emphasise the dynamic nature of the relationship between different media, Hayles explains:

when literature leaps from one medium to another - from orality to writing, from manuscript codex to printed book, from mechanically generated print to electronic digitality - it does not leave behind the accumulated knowledge embedded in genres, poetic conventions, narrative structures, figurative tropes, and so forth. Rather, this knowledge is carried forward into the new medium typically by trying to replicate the earlier medium's effects within the new medium's specificities (2008: 58).

However, the shift to the chirographic also creates the context for new materialisations of poetry through this medium. The written word, which provided poets with the ability to privately respond to the inert marks on the page as evidence of their subjectivities, undoubtedly facilitated the dominant development of modern lyric poetry, defined by Laurence Lerner as 'the most personal kind of poem' and as distinct from the 'resonant impersonality' of its ancient form (1987: 46). It also undoubtedly afforded the affective myths of individual genius and self-expression intrinsically bound up with it. Textuality is also ultimately what allows poems to be freed from the demands of the mnemonic, thus facilitating the free verse forms of the modern age. Shape or concrete poetry is also made possible by the remediation of poetry into a visible art. The material of the page thus generates the poems of its age.

The words inscribed on the page also themselves provide a distinctive material and class of stimuli. Timothy Clark usefully describes writing as 'improvised performance mediated by self-reading' (1997: 15), highlighting how engagement with materials through processes of self-reading constitutes an integral and significantly underestimated component of the creative process. The words on the page introduce what Clark describes as 'the ventriloqual effects of received literary codes and their constraints' (24), including a 'residual orality' (61), which trigger intertextual recognitions and parameters for the poet's work of revision, figured as the work of creation. Written words also form visual cues that are experienced in not only cognitive or intellectual but also sensorimotor and affective ways. In Literary Reading, Cognition and Emotion: An Exploration of the Oceanic Mind, Michael Burke details how reading involves 'seeing, thinking and feeling' (2011: 26). As he explains, 'text comprehension, and especially literary text comprehension, is far more than mere semantic decoding of words' (135). Instead, the work of mirror neurons means that our bodies enact and 'feel' the semantic content of the words, simultaneously evoking cognitive and affective responses bound up with personal and textual memories. Indeed, according to Clark, it is the affordances of the written materials on the page that give writers the sense of being inspired by a muse or something 'other.' For Clark, Romantic inspiration is essentially a 'textual effect' (1997: 26) or an experience 'determined by the material parameters of composition' (40).

As $\mathrm{Wu}$ recognises, the Romantic myth of spontaneous inspiration, deriving from a theological understanding of the Bible's authors as 'possessed of the Holy Spirit' during composition (2015: 49), is central to the Romantic myth of individual genius. However, 
this is another myth thoroughly undermined by the actual practice of Romantic poets. Wu reviews how Byron's Don Juan (1819), for instance, emerged from many months of revisionary practice (49). He also re-examines Coleridge's wilful misrepresentation of the composition of 'Kubla Kahn,' which the poet claimed he 'received' during an opium dream but which in fact took many months to compose, undergoing various productive revisions during the period of its emergence (52). However, ideologies of inspiration continue to permeate understandings of creativity, having a clear effect in contemporary creative-writing classrooms, where students often demonstrate a misconception of and resistance to the compositional work of revision. In response, the poet Mark Yakich encourages his student writers to think of revision not as 'correction' but as 'opening up the possibilities of what's already on the page' (2016: 154). He writes: 'Amateur writers expect their lines to descend from on high or to be whispered in their ear by a muse. Nothing could be further from what happens in practice. For writing is all practice' (196). Writing, in other words, materialises.

Most writing, even if it is ultimately published in the form of the printed codex, is now undertaken on digital platforms. As Hayles puts it, 'digital technologies are now so thoroughly integrated with commercial printing processes that print is more properly considered a particular output form of electronic text than an entirely separate medium' (2008: 5). It is also the case that the digital has remediated the chirographic so that writing on a screen is commonly viewed as a substitute for writing on a page. However, the networked computer has undoubtedly introduced capabilities, including the kind of informational access and manipulability of text responsible for the 'uncreative writing' of Kenneth Goldsmith's so-called American Trilogy, comprised of The Weather (2005), a transcription of New York city weather reports; Traffic (2007), a day's worth of traffic reports; and Sports (2008), which replicates the TV commentary on a baseball game. The electronic medium is also refashioning the writing space in ways that, as Hammond puts it, "force us to reconsider our sense of the "literary" by making it possible to present text and image alongside modalities that are impossible to store on page: sound, video, threedimensional color images, and so on' (2016: 41). These new multimedia capabilities have resulted in the emergence of Cin(E)-Poetry and Flash poetry, for instance, which bring together sound and vision, once again remediating oral poetic tradition.

While enthusiasts such as Hammond have hailed 'a digital literary renaissance' that will bring about a 'golden age of literature' (37), it is in fact difficult to predict how future poetry will materialise. As Bolter warns, 'it would be foolish to doubt the power that entrenched hierarchies will bring to bear in forcing new media technologies into traditional formal, lyrical, and economic structures' (2011:212). However, given that the top word of 2014 was an emoji of a love heart (Simanowski 2016: 387), turning away from the new audio-visual 'languages' of the digital would seem equally foolish. In fact, it is ultimately the argument of this paper that understanding creativity as a process that emerges from engaging with materials gives students the best chance of productively mobilising new technologies and participating, as Bolter puts it, 'in our ongoing cultural redefinitions of self, knowledge, and experience' (2011: 189).

\section{Conclusion}

For decades psychologists have relied on psychometric tests such as the Torrance Test for divergent thinking, Sam Mednick's Remote Associates Test and the popular Alternative Uses Text or (AUT) to diagnose creativity in individuals. Indeed, as Arne Dietrich reveals, these tests continue to inform the work of neuroscientists who use fMRI scans to locate creativity in brains (2015: 33). It is also the case that the culture industries, as Johanna Drucker writes, continue to be 'emblematically stamped with the image of the 
One, the Individual, whose unique and original experience is uttered as a cry into the overwhelming sublimity of nature or against the supposedly crushing banality of culture' (2015: 91). Such beliefs, as we have seen, render materials or media invisible as agents in creative processes.

This paper attempts to challenge a post-Romantic individualistic view of creativity on the basis that the mystification of creativity serves neither creativity research nor students of creative writing. Understanding creativity as materialised 'enactment and experimentation rather than seeing or representation,' as Tanggaard recommends (2014: 121), can arguably result in many benefits. Students might be more likely to read because they understand the generative rather than threatening nature of tradition. They might better appreciate the material process of revision because they understand the complex agency of words written and simultaneously read on the page or screen. They might be less likely to receive feedback and advice badly, as a result of perceiving their writing not as the expression of their deepest self but as a socio-material activity emerging in a cultural domain. They might also be more capable of participating in our present media environment because they embrace creativity as a relational dynamic between subjects and materials in an ever-changing social world.

\section{Works Cited}

Abra, J 1988 Assaulting Parnassus: Theoretical Views of Creativity, Lanham, Maryland: University Press of America.

Allington, D 2011 'The Production of Creativity,' in J Swann, R Pope \& R Carter (eds) Creativity in Language and Literature: The State of the Art, Houndmills, Basingstoke: Palgrave Macmillan, 277-289.

Bolter, J D 2011 Writing Space: Computers, Hypertext, and the Remediation of Print, London: Routledge.

Bolter, J D and R Grusin 2000 Remediation: Understanding New Media, Cambridge, Massachusetts: MIT Press.

Bourdieu, P 1993 The Field of Cultural Production: Essays on Art and Literature, Cambridge, United Kingdom: Polity.

Brinkman, S \& L Tanggaard 2010 'Toward an Epistemology of the Hand,' Studies in Philosophy and Education, 29: 243-257.

Burke, M 2011 Literary Reading, Cognition and Emotion: An Exploration of the Oceanic Mind, New York: Routledge.

Carter, R 2004 Language and Creativity: The Art of Commontalk, London: Routledge.

Clark, T 1997 The Theory of Inspiration: Composition as a Crisis of Subjectivity in Romantic and PostRomantic Writing, Manchester: Manchester University Press.

Csikszentmihalyi, M 1988 'Society, Culture, and Person: A Systems View of Creativity,' in R J Sternberg (ed) The Nature of Creativity: Contemporary Psychological Perspectives, Cambridge, United Kingdom: Cambridge University Press, 325-339.

Dissanayake, E 2000 Art and Intimacy: How the Arts Began, Seattle: University of Washington Press.

Drucker, J 2015 'Humanist Computing at the End of the Individual Voice and the Authoritative Text,' in P Svenson and D T Goldberg (eds) Between Humanities and the Digital, Cambridge, Massachusetts: MIT Press, 83-93.

Fortunati, L \& J Vincent 2014 'Sociological Insight on the Comparison of Writing/Reading on Paper with Writing/Reading Digitally,' Telematics and Informatics, 31: 39-51.

Glaveanu, V P 2010 'Principles for a Cultural Psychology of Creativity,' Culture and Psychology, 16(2): 147-163.

Hammond, A 2016 Literature in the Digital Age, New York: Cambridge University Press. 
Hayles, N K 2008 Electronic Literature: New Horizons for the Literary, Indiana: Notre Dame.

Hayles, N K \& J Pressman (eds) 2013 Comparative Textual Media: Transforming the Humanities in the Postprint Era, Minneapolis, Minnesota: University of Minnesota Press.

LaTour, B 2005 Reassembling the Social: An Introduction to Actor-Network-Theory, Oxford: Oxford University Press.

Lerner, L 1987 'What is Confessional Poetry?' Critical Quarterly, 29(2): 46-66.

Merleau-Ponty, M 1976 (1962) Phenomenology of Perception, C Smith (trans) London: Routledge \& Kegan Paul.

Moffitt, J 2005 Inspiration: Bacchus and the Cultural History of a Creation Myth, Leiden, Netherlands: Brill.

Ong, W 2013 (1982) Orality and Literacy, Oxford: Taylor and Francis.

Piper, A 2009 Dreaming in Books: The Making of the Bibliographic Imagination in the Romantic Age, Chicago: University of Chicago Press.

Redfield Jamison, K 1993 Touched with Fire: Manic-depressive Illness and the Artistic Temperament, New York: Free Press.

Shelley, P B 1965 (1840) 'A Defense of Poetry', in R Ingwen \& W Peck (eds) The Complete Works of Percy Bysshe Shelley, (vol 7) London: Gordian.

Simanowski, R 2016 'Creativity and Digital Text,' in R H Jones (ed) The Routledge Handbook of Language and Creativity, London: Routledge, 383-97.

Taipale, S 2015 'Bodily Dimensions of Reading and Writing Practices on Paper and Digitally,' Telematics and Informatics, 32: 766-775.

Takolander, M 2015 'From the "Mad" Poet to the "Embodied Poet": Reconceptualising Poetic Creativity through Cognitive Science Paradigms,' TEXT 19(2).

Takolander, M 2016 'A Dark/Inscrutable Workmanship: Shining a Scientific Light on Poiesis,' Axon: Creative Explorations $\mathrm{C} 1$.

Tanggaard, L 2012 'The Sociomateriality of Creativity in Everyday Life,' Culture and Psychology, 19(1): 20-32.

Tanggaard, L 2014 'The Socio-materiality of Creativity: A Case Study of the Creative Processes in Design Work,' in V-P Glaveanu (ed) Rethinking Creativity: Contributions from Social and Cultural Psychology, Hoboken, New Jersey: Taylor and Francis, 110-124.

Wu, D 201530 Great Myths About the Romantics, Malden, Massachusetts: John Wiley \& Sons.

Yakich, M 2016 Poetry: A Survivor's Guide, New York: Bloomsbury. 